\title{
UNIVERSIDADE ABERTA À TERCEIRA IDADE: UMA TENTATIVA DE EMANCIPAÇÃO
}

\section{UNIVERSITY OPENED FOR THE ELDERLY: AN ATTEMPT TO EMANCIPATION}

\author{
Maria Carolina Gobbi dos Santos Lolli ${ }^{1}$ \\ Luiz Fernando Lolli ${ }^{2}$ \\ Eliane Rose Maio ${ }^{3}$
}

\section{RESUMO}

O presente texto tem por objetivo analisar o papel que a Universidade Aberta à Terceira Idade tem na sociedade atual considerando seu histórico. Tendo em vista o aumento da população idosa no mundo todo, que também pode ser observado no Brasil, faz-se necessário ressaltar a importância e o significado da educação que pode, possibilitar o desenvolvimento de uma visão crítica sobre si mesmo e a sociedade em que está inserido, bem como possibilitar novas oportunidades. A herança deixada por Pierre Vellas se multiplicou pelo mundo todo, chegando ao Brasil na década de 1970 e à Maringá no ano de 2009, com a UNATI/UEM. O presente texto nos faz perceber que a participação nas UNATIs espalhadas pelo mundo, implica também uma participação mais efetiva na sociedade, na tentativa da busca pela autonomia. Prezando por abordagem multidisciplinar no currículo e na metodologia de trabalho, estas instituições priorizam o processo de valorização da terceira idade analisando constantemente os diversos aspectos: biopsicológico, político, espiritual e sociocultural, tendo como finalidade integrar esses cidadãos à sociedade contemporânea tornando-os mais ativos, alegres e participativos.

Palavras-chave: Universidade aberta à terceira idade - Educação permanente - Educação não formal.

\section{ABSTRACT}

This text aims to analyze the role that the Open University of the Third Age has in today's society considering its history. We must consider the increasing elderly population worldwide, which can also be observed in Brazil, it is 
necessary to emphasize the education importance. The education can means a critical view development for elderly as well as enable new opportunities. The legacy of Pierre Vellas multiplied all over the world, coming to Brazil in the 1970s and Maringa in 2009, with UNATI / UEM. This text makes us realize that participation in UnATls run around the world, also implies a more effective participation in society, in an attempt to search for autonomy. Unpretentiously multidisciplinary approach in curriculum and methodology of work, these institutions prioritize the process of valuing seniors constantly analyzing the various aspects: bio-psychological, political, spiritual and socio-cultural, and aims to integrate these citizens to contemporary society making them more active joyful and participatory.

Keywords: Open to Seniors University _ continuing Education _ Non-formal education

\section{INTRODUÇÃO}

O envelhecimento da população é um fenômeno mundial marcado no século $X X$ e que vem se instalando rapidamente. Este fato, explicado pela baixa fecundidade e mortalidade que culmina no aumento da expectativa de vida, pode ser diretamente relacionado às melhorias na qualidade de vida $e$ aos avanços da medicina e da tecnologia (NOVAES, 2007).

No Brasil, podemos também perceber tal realidade, e, portanto, fica clara a necessidade do tema ser discutido e acima de tudo, estudado. Para ilustrar tamanha importância, segundo o censo de 2000, realizado pelo Instituto Brasileiro de Geografia e Estatística (IBGE, 2000), idosos e idosas correspondiam a 14,5 milhões de pessoas ou $8,6 \%$ da população total do nosso país. Já no censo de 2010, este grupo passou para 20,6 milhões de pessoas, correspondendo a 10,8\% da população mundial (IBGE, 2010). E esta progressão continua já que segundo dados do mesmo Instituto, nos próximos 20 anos, a população com mais de 60 anos de idade deverá ultrapassar 30 milhões de pessoas. 
Para grande parte das pessoas idosas, a idade traz diversas alterações para seu cotidiano, listadas por Pascual (2002), como por exemplo: perda do status profissional, resultante da aposentadoria; insegurança e sentido de inutilidade; perda de energia pelo comprometimento de condições de saúde por doenças, exigindo mais cuidados médicos, despesas, atenção familiar; perdas familiares, afetivas e sociais que reduzem seus relacionamentos; falta de oportunidades sociais e de lazer; transformações físicas e hormonais e de tônus vital que trazem a necessidade da aquisição de novos hábitos de vida.

Diante disto, Neri (2001) aponta como necessária a assistência ao idoso visando seu bem estar, sua autonomia, sua independência e inserção familiar e social para que ele consiga viver ativo, participativo e produtivo, já que esta constitui uma fase do desenvolvimento humano tão importante quanto às demais, que merece toda atenção e dedicação por parte dos pesquisadores, da família, da sociedade e do Estado, por meio do planejamento e da operacionalização das políticas públicas nesta temática.

A educação tem-se constituído o eixo central para a necessidade de engajamento social do idoso, propiciando um real aprendizado: a naturalidade de viver e de envelhecer, trabalhando, portanto, processos que caracterizam não só o envelhecimento seja ele biológico, psicológico ou sociocultural, mas a dinâmica da própria aprendizagem que deve situar-se diretamente a partir da experiência, já que nenhuma necessidade é mais humana do que a de perceber o significado da própria existência. Neste sentido, devem ser consideradas ações pedagógicas que levem em conta estímulos visuais, os comportamentos dos idosos (muitas vezes contidos), os diferentes ritmos sensório-motores, história pessoal, a possibilidade de interagir e ampliação do conhecimento proporcionado pelo uso de filmes, aulas práticas, discussões, atividades em grupo (NERI, 2001).

Cachione (2003) menciona que os programas educacionais para os mais velhos tem procurado atender estas necessidades, trabalhando com vários procedimentos pedagógicos a fim de despertar a consciência crítica para a busca do envelhecimento bem-sucedido. O desafio que se apresenta é o de gerar interesse pelo que se pretende ensinar, de modo que o idoso empregue esforço e dedicação para aprender. Este aprendizado entusiasmado, quando 
atingido, possui valor muito relevante em relação ao aprendizado convencional de pessoas em atividades escolares ou de universitários convencionais, uma vez que, além dos benefícios daquele aprendizado, este carrega potencialmente a condição de devolver a alegria a alguém, evitar ou atrasar doenças e contribuir pela busca do engajamento pleno na vida ao se deparar com a velhice. Além do que, por meio da educação continuada, programas educativos tem possibilitado aos idosos atualização, aquisição de conhecimentos e participação em atividades culturais, sociais, políticas, de lazer e de participação no setor mercadológico de forma economicamente produtiva.

\section{A EDUCAÇÃO PARA A PESSOA IDOSA NO BRASIL}

Acreditamos que existam muitas formas de se destacar o valor de pessoas em processo de envelhecimento de modo mais efetivo, especialmente reconhecendo a importância de suas habilidades para contribuir no dia a dia, compartilhando experiências, dividindo responsabilidades, entre outros. Para tanto, os idosos precisam vencer os muitos desafios impostos pela sociedade e pelo próprio processo do envelhecimento e buscar novos espaços para a realização de atividades produtivas ou prazerosas, que elevem sua autoestima e desenvolvam a sua criatividade.

Ao realizarmos um estudo prévio na legislação brasileira, verificamos que ela é comprometida com a busca por mudanças no que se refere à maneira preconceituosa de como o idoso é tratado. Percebemos que ela é baseada no objetivo de integrar os indivíduos mais velhos à sociedade.

Cabe-nos então, citar a atual Constituição da República Federativa do Brasil, de 1988, no Título VIII - Da Ordem Social, no Capítulo VII - Da Família, da Criança, do Adolescente e do Idoso, Art. 230. O documento prevê que:

A família, a sociedade e o Estado têm o dever de amparar as pessoas idosas assegurando sua participação na comunidade, defendendo sua dignidade e bem estar e garantindo-lhes o direito à vida (BRASIL, 1988, p. 12). 
Com o objetivo de assegurar os direitos dos idosos brasileiros, criando condições para assegurar-Ihes autonomia, integração e participação efetiva na sociedade, a lei 8.842 datada de 4 de janeiro de 1994, instaura a Política Nacional do Idoso/a no Brasil e cria o Conselho Nacional do Idoso. E para consolidar os direitos já assegurados, em 2003, foi designado o Estatuto do Idoso, referente à Lei n.10.741/2003 (BRASIL, 2003).

O Estatuto do Idoso é composto por 230 artigos que tratam de transporte coletivo, violência, saúde, trabalho, habitação, lazer, cultura, esporte, educação e entidades de atendimento ao idoso. Dentre os artigos que integram este documento tão importante, interessa-nos predominantemente o Título II, Dos Direitos Fundamentais, em seu Capítulo V, Da Educação, Cultura, Esporte e Lazer.

O artigo 20 prevê que o idoso "tem direito à educação, cultura, esporte, lazer, diversões, espetáculos, produtos e serviços que respeitem sua peculiar condição de idade" (BRASIL, 2005, p.18). Assim, podemos afirmar que um dos grandes desafios impostos pelas políticas públicas de atendimento aos idosos é a promoção da inclusão por meio da educação enquanto um espaço aberto para questionamentos, decisões, capacitação e diálogo. Esta colocação pode ser ilustrada pelas palavras de Oliveira (2011, p. 90),

(...) tão fundamental quanto a cidadania, é o direito pela educação, pois não se alcançará a cidadania sem que haja conhecimento pleno deste direito. Logo, pensar a educação para a terceira idade, é pensar mais que uma ocupação para o idoso, é permitir uma ação intensiva e intencional para que este sujeito se perceba, entenda seu entorno social, político e econômico, como também não seja ludibriado ou tenha seus direitos negligenciados.

Especificamente em relação à educação, o Estatuto do Idoso (BRASIL, 2005) garante que cabe aos governos criar "[...] oportunidades de acesso ao idoso à educação, adequando currículos, metodologias e material didático aos programas educacionais a ele destinados" (art. 21, p.18). Garante ainda que os cursos especiais para esta faixa etária devem incluir conteúdos referentes às técnicas de comunicação e computação visando mais integração destes indivíduos na sociedade contemporânea. O documento também reconhece a importância da inserção de "conteúdos voltados para o envelhecimento e valorização de idosas e idosas em diversos níveis de ensino 
formal, com o intuito de banir o preconceito e produzir conhecimentos sobre o processo" (art. 22, p.19).

O artigo 25 do Estatuto do(a) Idoso(a) contempla o incentivo à produção de materiais como livros e periódicos com conteúdo pertinente aos(às) idoso(as) bem como a criação de Universidades Abertas à Terceira Idade.

Nas palavras de Pascual (2002), envelhecer dignamente é direito de todos(as), sem limite de idade, vendo-se respeitado(a) e não como descartável pelo tempo. $\mathrm{O}$ autor reconhece que a legislação brasileira possibilita um grande avanço social já que não garante apenas o direito dos(as) idosos(as), mas também a educação das novas gerações para que estejam mais bem preparadas para entender o processo do envelhecimento.

Apesar disto, Marx e Engels (2010, p. 126) nos perguntam: "A educação é idêntica para todas as classes?" Os Idosos teriam as mesmas chances que os mais novos têm no que se diz respeito à educação?

Consideramos a educação formal e não formal como meio fundamental para conscientização e construção da cidadania e ainda como ponto de partida para a ação reflexiva sobre os processos que envolvem a vida. Nesse sentido, Marx e Engels (2010), nos fazem pensar sobre a necessidade de transformação. Os autores destacam a divisão da sociedade em classes. Em uma sociedade capitalista, a mudança deste quadro deve ser tomada como uma busca constante, para que o conhecimento do Homem possa vir a ser de todas as pessoas, independente da classe social, gênero ou idade.

Pascual (2002) confirma que pode soar um pouco estranho, aos ouvidos de algumas pessoas, o tema 'educação para idosos(as)', seja ela formal ou não formal. Esse estranhamento pode ser entendido pela ideia, ainda dominante da nossa cultura de que 'educação' e 'velhice' são expressões incompatíveis e que idosos já estariam fora do processo da aprendizagem, entendido como se tivesse uma data estabelecida e um ritmo previamente demarcado.

Reafirmamos diante do exposto que a educação tem-se constituído, mais do que nunca, em um elemento significativo também para as pessoas idosas. Certamente, ela tem um papel transformador importantíssimo. 
Ressaltamos desta maneira, que todas as idades têm necessidades de diferentes tipos de conhecimentos e, portanto a educação deveria ser um processo contínuo vivido pelo ser humano. Fazendo uso das palavras de Snyders (1981, p. 105), "a escola é um local de luta, o teatro em que se defrontam forças contraditórias e isto porque já faz parte da essência do capitalismo ser contraditório, agir contra ele próprio [...]". No entanto, Adorno (1996, p.388) adverte:

Reformas pedagógicas isoladas, embora indispensáveis, não trazem contribuições substanciais. Poderiam até em certas ocasiões, reforçar a crise, porque abrandam as necessárias exigências a serem feitas aos que devem ser educados e porque revelam uma inocente despreocupação diante do poder que a realidade extrapedagógica exerce sobre eles.

Ao nos referirmos às mudanças, temos claro, conforme Saviani (2008), que são inúmeros os desafios pedagógicos a serem enfrentados, pois não basta a teoria para fomentá-las, necessita-se da ação pedagógica travada no campo da escola, uma ação que tenha como início das discussões, a prática social, para que depois de elaborada possa novamente retornar à prática social que toque em todas as pessoas. Não nos referimos aqui somente à escola como estabelecimento destinado para a formação, mas também às instituições sociais - como, a igreja, os clubes, os espaços de convivência - já que a sociedade igualmente exerce o papel de transmitir, conservar e aperfeiçoar os valores e conhecimentos que adquiridos diariamente (ADORNO, 1995).

\section{HISTÓRICO DAS UNIVERSIDADE ABERTA À TERCEIRA IDADE}

O fenômeno mundial do aumento do número de idosos despertou em várias nações a necessidade das sociedades reconhecerem primeiro a existência destes e com isto, a importância social e as necessidades das pessoas com mais idade. De encontro com esta ideia, Adorno (1995) assina o fato de a emancipação pessoal ser imprescindível para as sociedades. Surgem então nesta prerrogativa, as primeiras iniciativas para a educação dos indivíduos mais velhos. 
Com este argumento, cabe citar o conteúdo de um texto publicado, em 1976, por Moody que conceitua quatro modelos de educação para a velhice:

O primeiro modelo, e mais pessimista, não considera necessários investimentos para a educação dos idosos já que estes são improdutivos e dependentes. A respeito disto, podemos citar Marx (2004, p.52) que explica o fato de que no mundo capitalista, "forma-se uma classe cada vez mais numerosa de trabalhadores que, graças à educação, tradição e costumes, suportam as exigências do regime tão espontaneamente como a mudança de estações". Esta classe de trabalhadores hoje, além dos fatores de sua formação, citados por Marx, já tiveram como recompensa seus anos de vida aumentados e, com a maior longevidade, a porcentagem de pessoas aptas para o trabalho aumentou mas, obviamente, ela não foi acompanhada de maior capacidade para produzir diretamente proporcional à idade, portanto não se faz necessário investir nesta camada improdutiva.

O segundo modelo descreve os serviços educativos para idosos como um 'remédio' e que deve ser ofertado na forma de entretenimento, lazer e contatos sociais. Não existe neste modelo nenhuma preocupação com uma pedagogia específica para os idosos, já que na época em que o documento foi escrito se acreditava que ele não mais se desenvolveria cognitivamente.

O terceiro modelo preconiza que a educação se define como meio de manutenção das habilidades e das experiências de idosos para que eles possam participar e interferir nos dilemas da sociedade, por meio de programas educacionais específicos organizados para eles e ainda de acordo com a vontade dos mesmos.

Já o quarto modelo fundamenta-se na ideia de autorrealização e de educação permanente, com 0 reconhecimento dos valores, direitos e oportunidades dos idosos.

Os dois últimos modelos têm para nós significância, já que fundamentam a educação para a terceira idade.

O talento não se encontra previamente configurado nos homens, mas, em seu desenvolvimento, ele depende do desafio a que cada um é submetido. Isso quer dizer que é possível 'conferir talento' a alguém. A partir disso a possibilidade de levar cada um a aprender 
pode intermédio da motivação converte-se numa forma particular do desenvolvimento da emancipação (ADORNO, 1995, p.170).

De tal modo, percebemos que o projeto de um currículo específico para as pessoas idosas deva contemplar atividades que estimulem a sua autonomia, responsabilidade social e integração na sociedade levando em conta a sua realidade, suas limitações, seus interesses. O que concorda com os ensinamentos de Adorno (1995) na insistência de que todos os conhecimentos que adquirimos durante a vida são válidos e não podem ser descartados nem desprezados.

Este desejo não é uma meta tão recente. Cachione (2012) descreve que depois da Segunda Guerra Mundial, em 1968, foram criadas as "Universidades do Tempo Livre", idealizadas e construídas na França pelos governantes. Estas instituições tinham por finalidade além da alfabetização de adultos transmitir informações sobre saúde, religião, política e trabalho com a intenção de ocupar o tempo livre dos aposentados e favorecer relações sociais entre eles.

Neste contexto pós-guerra, percebemos uma valorização das teorias humanistas e preocupação social que podem ser exemplificadas pela criação na Universidade de Ciências Sociais de Toulouse, a "Universitè du Troisième Âge (UTA)" - Universidade da Terceira Idade - por Pierre Vellas, especialista em Direito Institucional, em 1973 (Cachione, 2012).

\begin{abstract}
O professor pesquisou sobre velhice em outros países, conheceu tudo o que pôde sobre políticas internacionais para os velhos. Visitou hospícios, asilos e pensões de aposentados. Verificou que as oportunidades oferecidas aos idosos eram quase inexistentes. Tirar os idosos do isolamento, propiciar-lhes saúde, energia e interesse pela vida e modificar sua imagem perante a sociedade, foram os objetivos desse primeiro programa. As estratégias que embasaram a definição das atividades foi traçada a partir da história e dos dramas pessoais dos estudantes. Os problemas de alguns eram amostras de uma realidade generalizada: solidão, isolamento, depressão, problemas de saúde (CACHIONE, 2012, p.3).
\end{abstract}

Cachione (1999) explica que a verdadeira intenção do professor Vellas era abrir a universidade a todos os idosos, sem exceção, para oferecerIhes atividades artísticas, intelectuais, e físicas. Entretanto conseguiu extrapolar este desejo, alcançando o feito do programa "Universidade da Terceira Idade" 
(UTI) ultrapassar as fronteiras da França com contribuições em pesquisas para a melhoria da qualidade dos idosos e com uma metodologia própria de estímulo para reflexões, consciência crítica e o exercício da cidadania.

Cachione (1999), conta que outras Instituições no mundo também implantaram o programa UTI. Primeiro em 1975, a Polônia com a criação da Universidade da Terceira Idade de Varsóvia e a Suíça, em Genebra, inaugura a "Fondation de L'Université Du 3a Âge". No mesmo ano, o programa se expandiu para universidades dos Estados Unidos, da Itália, da Espanha e do Canadá. Em 1976 foi vez do Japão. No ano de 1977 a Áustria implanta a Associação Austríaca de Cursos Universitários que organizou diversos cursos na área gerontológica em Viena, Gratz e Salsburg. O ano de 1979 foi marcado pela implantação do programa por universidades da Inglaterra, de Israel, de Jerusalém. A ex-União Soviética criou as Universidades de Saúde e de Longevidade e a Alemanha que ofereciam cursos para aposentados. Em 1987, na Suíça mais precisamente a Universidade de Zurique, inaugura a Universidade para Idosos (CACHIONE, 1999).

Por fim, na década de 80, esta ideia chega à América Latina, começando pelo Uruguai, Argentina, México e finalmente, Brasil. Na América Latina, o programa é acessível para todos os idosos sem limite de idade e nível escolar, como nos apresenta Bayley (1994).

O modelo francês predominante na Espanha, Alemanha, Suíça, França, Bélgica, Polônia, Portugal, Japão, Suécia e Argentina, conserva os princípios do sistema tradicional acadêmico, garantindo segundo Cachione (2012), acesso a diferentes cursos universitários, aulas, grupos de estudos, oficinas de trabalhos, excursões e programas de saúde. O autor ainda nos informa que os ajustes na metodologia ou nos cursos são feitos de acordo com as necessidades, diferenças e grau de autonomia de quem frequenta.

O modelo britânico proposto pelos professores Peter Laslett e Michael Young, em 1981, na Universidade de Cambridge, defende que a formação e as experiências ao longo da vida constituem uma gama de conhecimentos importantes para serem compartilhados com indivíduos da mesma idade e também com outras gerações. Este modelo é bem aceito e predominante na Grã-Bretanha, Austrália e Nova Zelândia (HERBERSTREIT, 2006). 
Cachione (2012) ainda nos mostra que com a intenção de atender as necessidades e a hetogeneidade da população idosa, algumas regiões optam por características dos modelos britânico e francês. Cachione (1999) complementa a ideia assegurando que esta mistura atende bem diferentes contextos locais e institucionais. Segundo ela é o que acontece ainda nos dias atuais nos Estados Unidos, Brasil, Canadá, Itália, China e Finlândia.

Em 1975, com o reconhecimento e a expansão mundial do projeto proposto por Pierre Vellas, foi fundada a Association Internationale des Universitès du Troisième Âge - AIUTA. Esta associação, integra instituições universitárias, de todas as partes do mundo, com o mesmo objetivo de contribuir para a melhoria das condições de vida dos idosos. Em 1981, já existiam mais de 170 instituições associadas à AIUTA e no ano de 1999, mais de cinco mil instituições conforme descrevem os estudos de Cachione (2003).

Fundamentadas no diálogo igualitário, na inteligência cultural, na capacitação e na solidariedade, as Universidades Abertas à Terceira Idade é um modelo de atenção baseado na diversidade e na equidade onde a premissa básica é o fato de todos terem o mesmo direito de pensar, de aprender o que desejam e o que necessitam em busca de uma melhoria na qualidade de vida (MARTUCCI; PURQUÉRIO, 2005). Nesse sentido baseados nos pressupostos pontuados por, Delors (1998, p.19) com o advento das UNATIS, a sociedade foi convidada a "compreender melhor o outro, e compreender melhor o mundo. Trata-se de aprender a viver juntos, desenvolvendo o conhecimento acerca dos outros, da sua história, tradições e espiritualidade."

Acreditamos que estas instituições difundidas em todos os continentes têm oferecido condições, para pessoas com mais de 60 anos de idade, de cuidar, de forma equilibrada, autônoma e produtiva, do cotidiano de suas vidas bem como dos seus valores éticos, políticos, sociais e culturais. Proposições que vão muito além das expectativas do professor Vellas ao propor este tipo de instituição que como já dito anteriormente, era da simples busca de preenchimento do 'ócio' ou ainda de ocupar o tempo vago dessas pessoas.

Falando um pouco da realidade das Universidades Abertas à Terceira Idade brasileiras, devemos referenciar o pioneirismo do, Serviço Social do Comércio (SESC) com os primeiros "Grupos de Convivência" e 
posteriormente com as primeiras Escolas Abertas para a Terceira Idade, como explica Cachione (2003, p.3):

\begin{abstract}
Nas décadas de 1960 e 1970, foram criados os primeiros programas com cunho educativo para os mais velhos. O SESC liderou este trabalho, que posteriormente, com a internacionalização da gerontologia, encontrou solo fértil nas universidades brasileiras. Nesse mesmo período, importamos e incorporamos a expressão terceira idade, presença predominante na denominação de grupos, centros e programas nacionais para pessoas idosas.
\end{abstract}

Em 1982 foi fundado na Universidade Federal de Santa Catarina, o Núcleo de Estudos da Terceira Idade (NETI) que implementou a realização de estudos e a divulgação de conhecimentos gerontológicos (GUEDES e VAHL, 1992).

Em 1988, foi fundada pela Universidade Estadual do Ceará, a Universidade Sem Fronteiras, que propôs várias atividades de extensão como a formação de grupos de pessoas idosas; apoio docente e cursos especiais para idosos; cursos e seminários sobre idosos.

Ainda no final da década de 80 foi criado um grupo de profissionais de diversas áreas do conhecimento interessado em questões relacionadas ao envelhecimento na Universidade Estadual do Rio de Janeiro, denominado Núcleo de Assistência ao Idoso (NAI).

Em 1990, a Pontifícia Universidade Católica de Campinas (PUC/CAMPINAS), institui a Universidade Aberta à Terceira Idade (UNATI). Este programa, muito próximo da proposta francesa, marcou a evolução da gerontologia educacional no Brasil já que foi responsável pela pulverização de programas voltados para idosos em vários Estados brasileiros como São Paulo, Pará, Rio de Janeiro, Ceará, Pernambuco, Goiás, Maranhão, Rio Grande do Sul, Distrito Federal e Paraná (CACHIONE, 2003). Outra informação importante sobre a UNATI da PUC/Campinas foi o fato deste ter sido o primeiro Programa a ser divulgado na mídia em caráter nacional, possibilitando um grande incremento de instituições congêneres em todo país (CACHIONE, 1999).

No Brasil, as UNATls podem ser encontradas com variadas denominações: 
Universidade Aberta à Terceira Idade; Universidade para a Terceira Idade; Universidade com a Terceira Idade; Universidade na idade Adulta; Universidade Alternativa; Universidade sem Limites; Universidade sem Fronteiras; Programa da Terceira Idade; Faculdade da Terceira Idade; Faculdade de Atuação Permanente; Núcleo de Estudo e Pesquisa ou Núcleo Integrado de Apoio a Terceira Idade; Centro Regional de Estudos e Atividades da Terceira Idade; Centro de Extensão em Atenção à Terceira Idade; Programa de Participação Permanente; Projeto Sênior; Atividade Física para a Terceira Idade; Curso de Extensão para a Terceira Idade; Grupo de Convivência; Grupo de Trabalho da Terceira Idade; Encontros para a Terceira Idade; Educação Continuada e Terceira Idade (CACHIONI, 2003, p.52).

Segundo Taam (2009), as UNATIs não se diferenciam somente nas denominações, mas também em outros pontos como: horários, formas de ingresso, pré-requisitos para participação, atividades, cursos oferecidos e organizações, mas todas de formas diferentes, "[...] contribuem para que o idoso seja autor e ator principal de sua própria vida" (TAAM, 2009, p. 46).

Além disso, todos esses programas compartilham de propósitos como:

(...) o de rever os estereótipos e preconceitos com relação à velhice; promover a autoestima e o resgate da cidadania; incentivar a autonomia, a integração social e a auto-expressão, e promover uma velhice bem-sucedida em indivíduos e grupos, essas instituições hoje se espalham por todo o país (CACHIONE, 2003, p. 38

Assim, compreendemos que as propostas e discursos estão preocupados com a qualidade de vida, a promoção da saúde, a manutenção da autonomia e a inserção social do idoso; outro ponto em comum é a oferta de oportunidades educacionais e culturais que possibilitem e promovam 0 desenvolvimento pessoal e coletivo dos idosos (CACHIONI, 2003).

Cachione (2012) afirma que na atualidade, as instituições de ensino superior particulares são as maiores investidoras nas UNATI, seguidas das estaduais e federais. A influência exercida pelo modelo francês pode ser evidenciada pelo vínculo com instituições de ensino formal bem como exigências em termos de assiduidade e horários. Entretanto, não podemos deixar de mencionar que muitos ajustes são realizados nos moldes britânicos, já relatados, para melhor adequar as atividades oferecidas à realidade dos frequentadores. 
No ano de 2009, nosso país contava com 100 Universidades Abertas à Terceira Idade. Atualmente existem 156 unidades espalhadas pelo Brasil. Especificamente no Paraná, o programa é desenvolvido na Universidade Estadual do Centro-Oeste do Paraná (Unicentro) nos campus Irati e Santa Cruz, em Guarapuava; na Universidade Estadual de Ponta Grossa (UEPG) e na Universidade Estadual de Maringá (UEM) (TAAM, 2012).

\section{A UNATI/UEM}

A Universidade Estadual de Maringá, preocupada com os idosos da região, antes mesmo da criação da Universidade Aberta à Terceira Idade da Universidade Estadual de Maringá (UNATI/UEM), esboçou um pré-projeto de atendimento para esta parcela da população oferecendo cursos nas áreas de Educação para a saúde, Arte e cultura, Conhecimentos sobre a terceira idade, Línguas estrangeiras, Informática e Atividades Físicas.

Stieltjes e Taam (2011) descrevem que a UNATI/UEM, idealizada pelo Professor Décio Sperandio, foi oficialmente designada em 14 de dezembro de 2009, como um órgão suplementar da Reitoria, o que permitiu uma presença mais sólida e significativa tanto no aspecto pedagógico quanto político, possibilitando a atuação no tripé que fundamenta as Universidades: o ensino, a pesquisa e a extensão (STIELTJES; TAAM, 2011).

A aula inaugural aconteceu no dia 7 de março do ano de 2010. $\mathrm{Na}$ ocasião foram oferecidas 340 vagas em 54 cursos ou atividades diferentes nas áreas de educação para a saúde, arte e cultura, conhecimentos sobre terceira idade, línguas estrangeiras, informática, oficinas de teatro, além de atividades físicas como dança e hidroginástica, ministrados por 44 professores(as) efetivos(as) da Universidade Estadual de Maringá.

Atualmente, a UNATI/UEM atende 400 alunos com idade igual ou superior a 60 anos de idade, ofertando 40 cursos gratuitos divididos e organizados em 6 eixos temáticos, a saber: "Arte e cultura"; "Processos e procedimentos comunicativos"; "Saúde física e mental", "Meio físico e social"; "Direito e Cidadania" e "Humanidades" 


\begin{abstract}
Os cursos são oferecidos em quatro dias da semana, nos turnos da manhã e da tarde; a carga horária varia de acordo com a natureza do curso e o conteúdo programático: $17 \mathrm{~h}, 34 \mathrm{~h}, 68 \mathrm{~h}$ ou $102 \mathrm{~h}$. As aulas são ministradas por professores da UEM e computadas em suas atribuições de ensino. As sextas feiras são reservadas para palestras, mini-cursos, reunião de grupos de pesquisa, etc... O aluno da UNATI escolhe os cursos que deseja fazer (não ultrapassando o limite de quatro cursos por semestre). O número de vagas é definido pelo docente responsável pelo curso (STIELTJES; TAAM, 2011. p.151).
\end{abstract}

Os cursos não têm cunho profissionalizante, então o aluno tem liberdade para escolher as atividades de ensino, de acordo com suas preferências. Além disso, todo o material necessário como livros, textos, materiais de pintura e desenho, entre outros, é disponibilizado gratuitamente, conforme relatam STIELTJES e TAAM (2011). Os autores (p.151) ainda salientam que "na UNATI/UEM nada é cobrado do aluno; fazê-lo seria reproduzir o longo e doloroso processo de exclusão vivido por muitos dos alunos".

Com a intenção de uma melhor apresentação da referida instituição, citamos os seus objetivos listados no texto "A UNATI da UEM: Educação e política" dos professores Claudio Stieltjes e Regina Taam (2011): Possibilitar às pessoas idosas o acesso à Universidade, como meio de ampliação do espaço cultural, pelo oferecimento de cursos e atividades que propiciem a atualização de conhecimentos, tanto gerais como específicos, aos interesses deste segmento; Estimular a participação da população idosa nas atividades sociais, políticas, econômicas e culturais da sua comunidade; Proporcionar informações que permitam a reflexão sobre o processo de envelhecimento; Proporcionar espaço de convivência e troca de experiências; Possibilitar ao idoso acesso a programas, serviços e recursos que atendam a seus interesses e necessidades, nas diversas unidades universitárias; Tirar os idosos do isolamento, proporcionando-lhes saúde, energia e interesse pela vida e modificando sua imagem perante a sociedade.

Percebemos que esses objetivos, que vêm de encontro à proposta de educação por toda a vida, tentam responder:

(...) ao desafio de um mundo em rápida transformação, mas não constitui uma conclusão inovadora, uma vez que já anteriores relatórios sobre educação chamaram atenção para esta necessidade de retorno à escola, a fim de estar preparado para acompanhar as 
inovações. É uma exigência que continua válida e que adquiriu, até, mais razão de ser (DELORS, 1998, p.19)

As turmas da UNATI/UEM são marcadas pela diversidade de nível de escolaridade, nível socioeconômico, de idade, de experiências de vida, de capacidades fisiológicas e condições físicas e de hábitos diários. Fazendo uso das palavras de STIELTJES e TAAM (2011), na UNATI/UEM existe subjetividade. Os autores complementam que os alunos são bastante críticos em relação aos ensinamentos recebidos, perguntando e comentando. Esta interação proporciona segundo Adorno (1995) uma compreensão entre alunos e professores não apenas em relação aos conteúdos das disciplinas, "mas em relação à sua realidade, complexa, surpreendente, desconcertante, sempre a desafiadora" (STIELTJES; TAAM, 2011. p.154).

Deste modo, a ideia defendida é que nunca é tarde para aprender, a UNATI/UEM proporciona a oportunidade para idosos e idosas redescobrirem formas de viver, adequando sua metodologia de ensino e conteúdos na transdisciplinaridade, ou seja, integrando diferentes campos do saber sem impor o domínio de uns sobre outros.

\footnotetext{
Sonhamos a UNATI que queríamos, lutamos por ela e fizemos do nosso sonho o sonho de muitos companheiros da academia [...] a UNATI/UEM passa a fazer parte da vida da universidade, apresentando-se como educação permanente. [...] Professores e coordenadores sabem que atuam com pessoas que trazem marcas de uma longa existência, onde valores e crenças foram construídos e algumas vezes destruídos. (STIELTJES; TAAM, 2011. p.151, 153).
}

Entendemos que a educação permanente, não formal, é um instrumento eficiente para valorização e para o reconhecimento do idoso como indivíduo participativo e merecedor de atendimento com qualidade em todos os seguimentos sociais.

Neste sentido, é necessário contextualizarmos o termo "Educação Permanente" idealizado em 1972, pela UNESCO no Relatório "Aprender a ser". (FAURE, 1972). O Relatório Faure (1972), como também é denominado, lança as bases da 'educação ao longo de toda a vida' ampliando a compreensão da educação formal tradicionalmente conhecida e apresentando conceitos de 
educação global (dentro e fora da escola) e educação permanente ao longo de toda a existência. Ele parte do princípio de que:

(...) uma educação para formar o homem completo, cujo advento se torna mais necessário à medida que coações sempre mais duras separam e atomizam cada ser, terá de ser global e permanente. Trata-se de não mais adquirir, de maneira exata, conhecimentos definitivos, mas de se preparar para elaborar, ao longo de toda a vida, um saber em constante evolução e de "aprender a ser" (FAURE, 1972, p. 10).

A educação ganha então uma concepção nova. Ela passa a ser concebida como 'um processo do ser'. Assim é reconhecido que o indivíduo pode também aprender com as experiências acumuladas. Assim, a educação

[...] tem lugar em todas as idades da vida e na multiplicidade de situações e das circunstâncias da existência. Retoma a verdadeira natureza, que é ser global e permanente, e ultrapassa os limites das instituições, dos programas e dos métodos que Ihe impuseram ao longo dos séculos (FAURE, 1972, p. 225).

Seguindo esta ideia, a Comissão Internacional sobre Educação para o Século XXI, sob a coordenação de Jacques Delors (1998) "Educação um tesouro a descobrir", propõe para a UNESCO, também considera esta forma de educação com a perspectiva da educação permanente mais ampla e atual. Isto é justificado pelo fato da educação ocupar cada vez mais espaço na vida das pessoas explicada pela evolução do mundo e da sociedade exigindo uma atualização contínua dos conhecimentos, visto que "uns saberes penetram e enriquece os outros" (DELORS, 1998, p. 104).

A educação permanente divulgada no texto tem como princípio:

(...) fazer com que cada indivíduo saiba conduzir seu destino [...] a educação ao longo de toda a vida torna-se assim, para nós, o meio de chegar a um equilíbrio mais perfeito entre trabalho e aprendizagem bem como ao exercício de uma cidadania ativa (DELORS, 1998, p. 105).

Nesta perspectiva de educação permanente unida ao fato da Universidade ser o espaço por excelência da busca por conhecimentos, pesquisa e democratização do saber, defendemos a ideia do ambiente universitário também ter espaço para o idoso. A partir do momento que ele se 
insere na comunidade acadêmica, acontece a interação intergeracional, fomentando debates sobre questões relativas ao envelhecimento e demonstrando que preconceito e discriminação sustentados socialmente e culturalmente não possuem nenhuma fundamentação científica. Assim, os indivíduos são preparados para compreender a si mesmo e também o outro, a partir das diferenças, necessidades, e igualdades de cada singularidade (DELORS, 1998).

\begin{abstract}
Além da tarefa de preparar numerosos jovens para a pesquisa ou para empregos, a universidade deve continuar ser a fonte capaz de matar a sede de saber dos que, cada vez em maior número, encontram na sua própria curiosidade um meio de dar sentido à vida. [...] Todas as universidades deveriam tornar-se "abertas" e oferecer a possibilidade de aprender em vários momentos da vida (DELORS, 1998, p. 144).
\end{abstract}

A educação surge como ferramenta para que aconteça o fortalecimento da autoestima, integração social e valorização das relações entre diferentes gerações dentro do ambiente acadêmico, espaço caracterizado por estar repleto de jovens, por ser gerador de novos conhecimentos (CACHIONE, 2003).

Cachione (2012) também explica que a participação nas UNATI implica uma maior inserção na sociedade. A autora ainda assegura que estas instituições com abordagens multidisciplinar priorizam 0 processo de valorização da terceira idade analisando constantemente os diversos aspectos biopsicológicos, político, espiritual e sociocultural, como finalidade integrar esses cidadãos ao cotidiano tornando-os mais ativos, alegres e participativos.

Acreditamos que a procura pela Universidade Aberta à Terceira Idade da Universidade Estadual de Maringá, atualmente, pode ser explicada por representar a oportunidade da participação social em atividades compatíveis com as reais capacidades dos(as) idosos(as). Adorno (1995), garante que a estimulação do entusiasmo das pessoas mais velhas, 0 satisfazer de suas necessidades e, muito particularmente, de outras novas aptidões, atividades propostas por estes programas vão ao encontro do desenvolvimento pessoal. 


\section{REFERÊNCIAS}

ADORNO, T.W. Teoria da semicultura. Educação e sociedade, v. 56, n. 10, p. 388-411, 1996.

ADORNO, T.W. Educação e emancipação. São Paulo: Paz e Terra, 1995.

BAYLEY, A. UTOPÍA Y EDUCATIÓN. UNI3: EI Derecho a Ser. Documento. Montevideo, Uruguai. 1994.

BRASIL. Ministério da Saúde. Perfil do idoso. Brasília, 2003. Disponível em www.saude.org.br, acesso em 20 de maio de 2014.

BRASIL. Estatuto do Idoso. Coord. André Arruda. Rio de Janeiro: Roma Victor, 2005.

BRASIL. Constituição da República Federativa do Brasil. Brasília: Senado Federal, $1988 . \quad$ Disponível em: <http://www.planalto.gov.br/ccivil_03/Constituicao/Constituiçao.htm>

CACHIONI, M. Universidades da Terceira Idade: Das origens à experiência brasileira. In: NERI, A. L. e DEBERT, G. G. (Orgs.) Velhice e Sociedade. Papirus. Campinas. 1999, p.141-178.

CACHIONI, M. Quem educa os idosos? Um estudo sobre professores de universidades da terceira idade. 1. ed. Campinas: Alínea, 2003

CACHIONI, M. Universidade da Terceira Idade: história e pesquisa. Kairós. Revista da Faculdade de Ciências Humanas e Saúde v. 15, n. 7, p.99 - 115, 2012.

DELORS, J. Educação: um tesouro a descobrir. São Paulo: Cortez, 1998.

FAURE, E. Learning to be: The world of education today and tomorrow. Unesco, 1972.

GUEDES, N. M. e VAHL, I. A. C. O despertar de uma força: Experiência da Universidade Federal de Santa Catarina com a população idosa. In: A população idosa no Brasil. I Seminário Nacional de Especialistas Multidisciplinares em 3a Idade. Belo Horizonte: Fundação João Pinheiro. 1992.

HERBESTREIT, L. K. Evaluation of the role of the University if the third age in the provisiono f lifelong learning. Tese. Pretória. Universidade da África do Sul, 2006.

IBGE - Instituto Brasileiro de Geografia e Estatística. Censo demográfico de 2000 e 2005. 
IBGE - Instituto Brasileiro de Geografia e Estatística. Censo demográfico de 2010.

MARX, K. A origem do capital: a acumulação primitiva. São Paulo: Centauro, 2004.

MARX, K.; ENGELS, F. Manifesto do partido comunista. Porto Alegre: L\&PM, 2010.

MARTUCCI, E.M.; PURQUÉRIO, M.C.V. Universidade Aberta da terceira idade: projeto pedagógico, 2005. Disponível em http://www.fesc.saocarlos.sp.gov.br/arquivos/pdfs/Microsoft\%20\%20Projeto\%20Pedagogico\%20UATI.pdf.

MOODY, Harry R. The meaning of life in old age. In: Aging and ethics. Humana Press, 1976. p. 51-92

NERI, A. L. Desenvolvimento e envelhecimento: perspectivas biológicas, psicológicas e sociológicas. Campinas/SP: Papirus, 2001.

NOVAES, M.R.C.G. Assistência farmacêutica ao idoso - uma abordagem multiprofissional. Brasília: Thesaurus, 2007.

OLIVEIRA, R. M. P. A saúde mental do idoso. In: FIGUEIREDO, N. M. A.; TONINI, T. Gerontologia atuação da enfermagem no processo do envelhecimento. 2를 Ed. São Paulo: Yendis, 2012, p. 209-228.

PASCUAL, C. P. A sexualidade do idoso vista com novo olhar. TRADUÇAO: Alda da Anunciação Machado. São Paulo: Loyola, 2002.

SAVIANI, D. Educação socialista, pedagogia histórico-crítica e os desafios da sociedade de classes. In: LOMBARDI, José Claudinei; SAVIANI, Dermeval (orgs.). Marxismo e educação: debates contemporâneos. 2. ed. Campinas: Autores Associados: HISTEDBR, 2008, p. 223 - 274.

SNYDERS, G. Escola, classe e luta de classes. 2. ed. Tradução de Maria Helena

Albarran. Lisboa: Moraes editora, 1981.

STIELTJES, C.; TAAM, R. A UNATI da UEM: educação e política. In: OLIVEIRA, Rita de Cássia da Silva; D'ALENCAR, Raimunda Silva (org.). As experiências de universidades abertas em um Brasil que envelhece. 1. ed. Curitiba: CVR, 2011, p. 141 - 159.

TAAM, Regina. A educação não formal do Idoso em universidades da Terceira Idade e Centros de convivência. In: Park, M. B., Groppo, L.A. (org.). Educação e Velhice. Holambra/SP: Setembro, 2009, p.39-49. 
TAAM, Regina. A UNATI na RENAD: A inclusão das Universidades Abertas à Terceira Idade na Rede Nacional de Atenção ao Direito do idoso. Cadernos de Pesquisa Pensamentos Educacional, da Universidade Tuiuti, 2012.

${ }^{1}$ Graduada em Farmácia pela Universidade Estadual de Maringá e em Pedagogia pelo UNICESUMAR. Mestre em Ciências da Saúde pela Universidade Estadual de Maringá. Atualmente é Mestranda do Programa de pós-Graduação em Educação da Universidade Estadual de Maringá. E-mail: profcarolinasantos@gmail.com.

2 Graduado em Odontologia pela Universidade Estadual de Maringá. Mestre em Ciências farmacêuticas pela Universidade Estadual de Maringá. Doutor em Odontologia Preventiva e Social - Pela Universidade Estadual Paulista (UNESPAraçatuba). Atualmente é docente adjunto do departamento de odontologia da Universidade Estadual de Maringá e da Faculdade Ingá de Maringá (UNINGÁ) e Coordenador do Mestrado Profissionalizante em Odontologia da UNINGÁ.

3 Graduada em Psicologia pela Universidade Estadual de Maringá. Mestre em Psicologia pela Universidade Estadual Paulista (UNESP - Assis). Doutora em Educação Escolar pela Universidade Estadual Paulista (UNESP - Araraquara). Pós Doutora em Educação Escolar pela Universidade Estadual Paulista (UNESP Araraquara). Atualmente é docente adjunta do departamento de Teoria e Prática da Educação da Universidade Estadual de Maringá. É também docente permanente do Programa de Pós-Graduação em Educação da Universidade Estadual de Maringá.

RECEBIDO EM: outubro/2014

APROVADO EM: novembro/2014 